\title{
Who Blames Corruption for the Poor Enforcement of Environmental Laws? Survey Evidence From Brazil*
}

\author{
Michaël Aklin \\ NYU
}

\author{
Patrick Bayer \\ University of Mannheim
}

\author{
S.P. Harish ${ }^{\dagger}$ \\ NYU
}

\author{
Johannes Urpelainen \\ Columbia University
}

2 February 2014

\begin{abstract}
Who blames corruption for the poor enforcement of environmental laws? The answer to this question is important since corruption is an important reason why environmental policies are not properly enforced, but previous studies of environmental public opinion do not address the issue. We analyze data from a survey fielded in Brazil in June 2012, immediately preceding the Rio+20 environmental summit. We test hypotheses on income, education, and perception of corruption as a cause of poor enforcement of environmental policy. We find that wealthy individuals are more likely to associate corruption with enforcement failure than poorer Brazilians. However, education is not associated with the belief that corruption is a primary cause of enforcement failure. These results suggest that since wealthy Brazilians have a higher exposure to corruption because of their interaction with government officials, they understand the role of corruption in policy failure. Conversely, the kind of general information that education offers does not raise concern about the role of corruption in environmental policy. The results have important implications particularly in democratic societies, where governments have stronger incentives to address the problem if concerned publics associate corruption with enforcement failure.
\end{abstract}

\footnotetext{
${ }^{*}$ We thank Leany Lemos for providing us with the data. We are grateful to Mario Chacon and My Seppo for comments on a previous draft.

${ }^{\dagger}$ Corresponding author. Department of Politics, New York University, 19 West 4th Street, New York, NY 10012, USA. Phone: +1-212-998-8500. Email: psr245@nyu.edu
} 


\section{INTRODUCTION}

Governments of many developing countries have written impressive environmental policies, but their effects on environmental quality are undermined by a lack of rigorous enforcement (Ascher, 1999; Bechtel and Tosun, 2009). While the lack of bureaucratic resources matters for monitoring and oversight of industry groups, corruption is a key facet that prevents effective environmental policy (Fredriksson, Vollebergh, and Dijkgraaf, 2004; Cole, 2007). If corrupt officials accept bribes for looking the other way, individuals and organizations who pollute or destroy natural resources can avoid fines without changing their behavior (Hu, Huang, and Chu, 2004; Asproudis, 2011).

Who among the general public blames corruption for the poor enforcement of environmental laws? This question has both academic and policy relevance - it is particularly important in a democratic society, where governments are more responsive to concerns from the public than in autocracies (Stigler, 1972; Wittman, 1995). To the extent that voting constituencies worry about corruption as an impediment to environmental quality, governments have an incentive to implement anti-corruption reforms in environmental policy implementation. Without the public

perception of corruption as a cause of weak enforcement, the government has little incentive to combat corruption in environmental policy implementation. In consequence, environmental degradation goes unpunished.

Unfortunately, previous studies have shed little light on how publics perceive the importance of corruption as an impediment to enforcing environmental policy. While existing research has paid attention to the causes of environmental attitudes based on de facto characteristics such as wealth, education and political orientation (Van Liere and Dunlap, 1981; Dietz, Stern, and Guagnano, 1998; Dunlap, 1975; Dunlap and Mertig, 1995), there is little evidence on why people believe environmental policies are not improving environmental quality based on their de jure characteristics. As much as the demographic traits of people matter in shaping public opinion and government policy, their perceptions are equally important, given that they may motivate politicians to act (Ohdoko and Yoshida, 2012). Understanding public perceptions of the causes of enforcement failure can, therefore, help predict and facilitate future action by governments of democratic countries. In turn, such action shapes the effectiveness of environmental legislation 
on actual outcomes.

We present evidence from a June 2012 survey on environmental issues and policies in Brazil. The survey was conducted by DataSenado, an official Brazilian government agency, in preparation for the Rio+20 United Nations Conference. It surveyed about 1, 200 respondents on their opinion on the environment and its regulation in the country. We use a question on the respondent's perception of corruption as the primary reason that hinders environmental law enforcement. Brazil is an interesting case to study because it is one of the world's biodiversity hotspots, suffers from severe environmental degradation (e.g. Amazonian deforestation), and has in place various environmental policies that are not being properly enforced (Drummond and Barros-Platiau, 2006; Fearnside, 2005; Andersen and Granger, 2007). Moreover, the failure of enforcement in the country is also associated with corruption (Tabarelli et al., 2005), and there has been little research on environmental public opinion in Brazil. ${ }^{1}$

Our primary interest is in the respective roles of income and education, and our findings suggest that personal wealth is an excellent predictor of the perception that corruption is responsible for the lax enforcement of environmental policy. We show that respondents who earn less than minimum wage in Brazil believe that corruption to be the primary cause of the loose enforcement of environmental regulations with a probability slightly higher than 0.20 ; however, this probability increases to more than 0.40 for respondents with the highest levels of income. These findings make sense, given that wealthier individuals interact more with government officials and have more opportunities to observe bribery and therefore associate corruption with enforcement failure in general (Mocan, 2008; Hunt and Laszlo, 2012).

By contrast, we do not find evidence for educational effects. Assuming education is a good proxy for being informed, the findings suggest that improved environmental awareness does not strengthen the link between corruption and the lax enforcement of environmental policy. While educated people have more access to media and, therefore, information about environmental problems, this information does not seem to strengthen the connection between corruption and environmental policy. One reason could be that the Brazilian media does not emphasize violations of environmental regulations. Another could be that the effect of education on awareness 
about corruption in environmental enforcement is offset by the selection of educated people into the service sector, where environmental issues are less pronounced than in agriculture and industry.

To set the stage, we begin with a review of environmental legislation in Brazil. We focus on how the environmental laws in the country have changed over time and the disconnect between the laws and its enforcement. Next, we review the literature on public perceptions of environmental policy failure and identify the key contributions of this paper to the fields of environmental politics, corruption and public opinion. In the following section, we list the main hypotheses on income and education and their relation to the perception of corruption and enforcement of environmental policy in Brazil. Then we present the research design focusing on the construction of the dependent, explanatory and control variables. Lastly, we present the results of our findings.

\section{ENVIRONMENTAL PROBLEMS AND LEGISLATION IN BRAZIL}

The fifth largest country in the world, Brazil houses a wide range of ecosystems. On the whole, the country's diverse climate conditions have made it home to approximately 1.8 million species constituting $13.1 \%$ of the world's biota (Lewinsohn and Prado, 2005). However, the large endowment of diverse ecosystems has also resulted in a number of problems in protecting them, especially the deforestation of the Amazonian rainforest (Goodland and Irwin, 1975; Booth, 1989; Setzer and Pereira, 1991; Moran, 1994). While these rates have had a positive correlation with the country's economic growth, it has also caused a loss in biodiversity, an increase in greenhouse gases and problems of pollution (Fearnside, 2005).

According to Drummond and Barros-Platiau (2006), environmental legislation in Brazil can be categorized into three major phases. During the period $1934-1964$, environmental protection was not a priority for the country. The Brazilian state undertook massive efforts to increase investment in the agricultural sector, formulating national codes for ore, wood, and other natural resource production. Any environmental laws that were put into place during this period was not done for the preservation of the environment but for how it could increase economic growth. ${ }^{2}$ 
In the second phase (1964 - 1988), state intervention in the agricultural economy continued, but there were some targeted regulations to preserve the environment. These included tackling land reform, becoming a signatory of the Biodiversity and Climate Conventions in 1972, creating the country's first national environmental agency (Special Secretariat for the Environment or 'Secretaria Especial do Meio Ambiente') in 1973 and enacting the Law of the National Environmental Policy in 1981. These measures were seen as a way to balance economic growth and environmental sustainability Drummond and Barros-Platiau (2006). It was only during the third phase (1989-present) that environmental law in Brazil began to follow a scientific basis and adhered to international standards (Drummond and Barros-Platiau, 2006). In 1989, the government established the Institute of the Environment and Renewable Natural Resources, a centralized agency that was responsible for executing and monitoring all environmental regulations (Rylands and Brandon, 2005), and after the 1992 Rio Summit, Brazil became a signatory to the Convention on Biological Diversity and protocols on Climate Change and Biosecurity (Fernandes, 1992).

Despite the above measures to protect the environment, these laws have not had their intended impact (De Oliveira, 2002). Notwithstanding the licenses, implementation, tax credits, and sanctions, deforestation levels in the Amazon basin have not decreased (Fearnside, 2005). Though areas have been identified as part of protective regions, these laws have not been enforced to ensure the preservation of the environment. Indeed, "the concept of protective forests is regularly enforced only in some of the more settled Brazilian regions, and even then only to a mild degree" (Drummond and Barros-Platiau, 2006: 88). The huge logging industry in Brazil, which accounts for about 3.5\% to the country's GDP (Fordaq, 2009), has also contributed to the depletion of the forest region in the country with their culling of newer trees and the estimated damage being almost twice the reaped levels (Veríssimo et al., 1992; Fearnside, 2005). More generally, Hochstetler and Keck (2007: 51) argue that

"While Brazilian environmental law is ample and often well formulated, those characteristics are not enough to guarantee its effective application. When Brazilians are asked about particular laws and their impact, one possible response is 'That law never caught on' (essa lei não pegou). The phrase captures the frequent gap between legal and substantive reality ... the rule of law has always been tenuous and its application profoundly unequal." 
In other words, Brazil is a country with an unusually wide gap between de jure and de facto environmental legislation. This makes the question of corruption as a cause of enforcement failure a central one. Though corruption in Brazil is lower than other big countries like India and China, it is still high compared to its Latin American neighbors (Transparency International, 2012). Illegal loggers, big polluting industries like oil, natural gas, and petrochemical production have been accused of flouting regulations to continue their polluting activities (Greenpeace, 2001; Tabarelli et al., 2005; Drummond and Barros-Platiau, 2006). Even when the culprits are caught, corruption in the legal industry results in prosecutors unwilling to pursue charges against the violators (Kellman, 2001-2002).

\section{ENVIRONMENT, CORRUPTION, AND PUBLIC OPINION}

The reasons behind the lax implementation of environmental laws can be many. For instance, the laws themselves may be inadequate, or there might not be proper oversight by bureaucratic agencies, a possible lack of environmental education among the populace, or a national consensus of favoring economic growth over environmental protection. This section details the role of corruption in enforcement failure and relates the issue to public opinion.

Several academic works have examined the link between corruption and environmental policy. For instance, Fredriksson, Vollebergh, and Dijkgraaf (2004) provide a theoretical model where the government achieves utility from two sources - bribes from capital groups and the social welfare of the general population. The bribes induce the government to relax its enforcement of environmental policy which this allows for higher productivity of both labor and capital. ${ }^{3}$ Their model presents a link between corruption and environmental enforcement where higher corruption levels are associated with greater incentives to relax implementation of environmental regulations and favor bribes from the industry over the general welfare of the population. Another related model is Farzin and Bond (2006) who examine the theoretical relationship between democracy and environmental quality. There is also some empirical evidence on the relationship between corruption and the environment. For instance, Welsch (2004) and Cole (2007) provide a cross-country analysis on the effect of corruption on different measures of pollution. Other 
scholars have also examined the the role of trade, FDI, and political stability mediating the relationship between corruption and environmental policy (Fredriksson and Svensson, 2003; Cole, Elliott, and Fredriksson, 2006; Damania, Fredriksson, and List, 2003). In addition to the above macro perspectives, there is some micro-level evidence of the link between corruption and environmental regulation in the form of case studies from South Africa, India, Venezuela, Mexico, and Nigeria (Sundström, 2012; Desai, 1998).

We contribute to the above literature by focusing on public opinion in Brazil, and specifically on corruption as a cause of environmental policy failure. While public opinion on environmental policy has been studied (Inglehart, 1995; Bloom, 1995; Dunlap and Mertig, 1995; Brechin and Kempton, 1994), these works do not examine why people believe environmental policies are failing. The focus on public opinion is also relevant in the Brazilian context. Before the 1980s, there was general public consensus that economic growth was favored over environmental protection, but this has changed over the last two decades (Drummond and Barros-Platiau, 2006; Mittermeier et al., 2005). This has also led to heightened calls for government policy to pay more attention to its effects on the environment, and the rise of political parties like the Workers' Party and the Green Party who have articulated clear environmental policies (Guimarães, 1991; Moran, 1994). Against this backdrop of increased environmental interest, we examine what Brazilians believe to be the primary impediments to improved environmental quality. We also contribute to the literature on corruption that focuses specifically on Latin America. For instance, Seligson $(2006,2002)$ uses survey evidence from the region to examine the differences between corruption perception and experience and their impact on regime legitimacy. In a similar vein, Fried (2012) studies clientilism in Brazil through a focus on conditional cash transfers and redistributive politics in the country. Further, Dobson and Ramlogan-Dobson (2012) present cross-country evidence to show the uniqueness of Latin American in the role of corruption and income inequality. In contrast, we focus on the role of corruption in the enforcement of environmental policies in Brazil. Specifically, we focus on the perception of corruption in the poor enforcement of environmental laws in the country. 


\section{HYPOTHESES ON INCOME, EDUCATION, AND ENVIRONMENTAL CONCERN}

There are a number of studies that have examined the nexus between demographic factors and environmental attitudes. The primary predictors of these perceptions include age, education, income, gender, and political ideology (Van Liere and Dunlap, 1981; Dietz, Stern, and Guagnano, 1998). We focus primarily on two of these factors - income and education. Both are known to have a profound impact on the environmental attitudes of the respondent, and this is particularly salient in Brazil, where there is a wide variation in both income levels and educational attainment. Our original contribution lies in explaining how individuals perceive the causes of environmental policy failure. Though we choose to focus on income and education, we control for the other possible factors in our empirical assessments.

Higher income levels are generally associated with more concern for the environment since wealthy individuals have already fulfilled their basic economic needs and can hence care more about the environment than poorer members of society (Van Liere and Dunlap, 1980; Inglehart, 1995). A related reason is that richer individuals have more disposable income and hence are willing to bear the cost of higher levels of environmental quality (Diekmann and Franzen, 1999). However, income is also known to have a strong relationship with corruption levels in society and

public perceptions of corruption. For instance, You and Khagram (2005) argue that richer people in society are able to lobby and bribe public officials and manipulate both the formulation and enforcement of laws. Moreover, it allows them to be more exposed to corruption and hence they are more likely to think that corruption is a primary reason for the lax implementation of laws. These attitudes towards the environment and corruption are not necessarily conflictual. There is evidence to show that respondents with higher income do not generally support increased government spending on the environment (Jones and Dunlap, 1992), possibly because of their exposure to corrupt public officials.

Cross-country evidence on perceptions of corruption supports this assumption. Mocan (2008) analyzes survey data from 49 countries, including Brazil. He finds that in developing countries, people in the upper $50 \%$ of the income distribution have a higher probability of being asked to pay a bribe than people below the median, even controlling for country characteristics or using 
country fixed effects. However, the relationship does not hold in industrialized countries. Hunt and Laszlo (2012) analyze detailed bribery data in Peru and Uganda. They find that in both countries, "the rich use officials more often, and among users, the rich are more likely to bribe. The benefit of bribery is avoidance of the poor service delivered to clients who refuse to bribe" (Hunt and Laszlo, 2012: 355). Both articles are consistent with the causal mechanism between income and corruption that we posit, namely, the idea that a high income increases exposure to corruption.

Given the above arguments, we expect wealthier individuals in Brazil to hold the belief that corruption is responsible for a lack of enforcement. In view of this experience with corrupt officials, they understand that corruption is a roadblock to the implementation of laws. When they see environmental protection failing, they associate the failure with their own experiences as victims or perpetrators of corrupt acts. A common finding in the literature, Damania, Fredriksson, and List (2003) show for a mix of developed and developing countries that corruption reduces the stringency with which environmental policy is implemented. Fredriksson, Vollebergh, and Dijkgraaf (2004) find a similar relationship for 11 industrial sectors in 12 OECD countries, while López and Mitra (2000) demonstrate that in a theoretical rent-seeking model corruption is expected to negatively affect pollution; Welsch (2004) verifies this empirically in a cross-sectional study.

Brazilian political culture may strengthen the association between income and the holding of the belief that corruption is responsible for the failed enforcement of environmental policy. As Hochstetler and Keck (2007: 51) write, "[t]he grotesque levels of social inequality that affect other aspects of Brazilian social and political life are strongly reflected in the legal system." In such a setting, where wealth is a way to avoid the legal punishment for violating law, individuals with high incomes are aware of the opportunities that the legal system offers for the privileged not to comply with environmental policies in the books. Exploiting such opportunities is a form of corruption because it requires officials to overlook a violation in exchange for some favor, such as a bribe, either now or in the form of a future quid pro quo. Given this reasoning, we hypothesize as follows. 
Hypothesis 1 (Income, Corruption, and Enforcement of Environmental Policy). Income is positively associated with the perception that corruption is the main reason for the loose enforcement of environmental policy in Brazil.

Other than income, education levels of individuals are also known to affect both environmental preferences and perceptions of corruption. For instance, educational attainment is positively associated with heightened awareness and more concern for the environment (Van Liere and Dunlap, 1980; Vining and Ebreo, 1990). The reason for this relationship is typically attributed to greater access to information and an ability to understand the complexities that come with preservation of the environment (Howell and Laska, 1992). Education is generally accepted to not only increase knowledge, but also change attitudes such as increased spending to protect the environment (Jones and Dunlap, 1992). Education is also known to have an impact on perceptions of corruption. Using the 2004 International Social Survey Program, Melgar, Rossi, and Smith (2010) show that education is a significant predictor of corruption perception. At a more micro level, Olken (2007) examines the effect of providing more information to individuals and shows that it changes people's perception of corruption.

Based on this reasoning, we consider the possibility that educated individuals in Brazil see corruption as a cause of the failure of environmental policy enforcement. If education creates awareness about both environmental problems and raises concerns about corruption in government and bureaucracy, then educated individuals may associate corruption and environmental policy failure more readily than their less educated counterparts. This argument makes particular sense in a country like Brazil where, as we have shown above, corruption is a real problem for the enforcement of environmental policy. The ties between corruption and environmental policy have been documented both theoretically and empirically in various contexts. Fredriksson, List, and Millimet (2003) show that corrupt bureaucrats under certain conditions have an incentive to weaken environmental policies to increase rents. In a similar vein, Fredriksson and Svensson (2003) model environmental policy as a function of corruption and political instability, and demonstrate that corruption has a negative effect on environmental regulations, at least when political stability is relatively high (a situation which applies to Brazil in our sample). Finally, 
using cross-national data, Pellegrini and Gerlagh (2006: 332) claim that "corruption stands out as a substantial and significant determinant of environmental policies."

Hypothesis 2 (Education, Corruption, and Enforcement of Environmental Policy). Education is positively associated with the perception that corruption is the main reason for the loose enforcement of environmental policy in Brazil.

\section{RESEARCH DESIGN}

To determine whether education or income is associated with the belief that corruption is the main reason that hinders the enforcement of environmental laws, we use a telephone survey conducted by DataSenado in preparation for the Rio+20 United Nations Conference on Sustainable Development in June 2012. ${ }^{4}$ The survey was conducted during the first two weeks of June 2012, where respondents were asked about their environmental policy preferences, their opinion on the trade-off between economic growth and environmental protection, and their views on current levels of environmental legislation in the country. To be part of the survey, the respondent had to be a resident of the country, at least 16 years of age, and have access to a landline telephone. $^{5}$ A two-stage sampling strategy was employed for the survey: in the first stage 119 municipalities, including all state capitals, were chosen via probabilistic sampling that included state capitals with probability one and municipalities with a probability equal to their percentage of the total population. For the second stage, quota sampling was used to select landline

telephone numbers since no master list of all telephone numbers exists in Brazil. ${ }^{6}$ This resulted in a total of 1,226 respondents.

This survey is one of the few systematic attempts to ascertain the opinion of Brazilians on the environment and its management. We primarily use one question from the survey: the respondent's opinion on the most important reason that hinders environmental law enforcement. Respondents were given six substantive choices: bad laws, inefficient oversight, corruption, economic growth, lack of environmental education, and social inequality (all of which are typical reasons for the lax implementation of environmental laws in Brazil), and respondents were only allowed to choose one of them. ${ }^{7}$ In addition to the above six substantive options, the survey 
also accounted for other possible reasons by giving respondents the options of 'other' and 'don't know'. The actual wording used for the above question in the survey is provided in the Supplementary Appendix.

We use the respondent's answer to the above question as the main dependent variable of our study. Specifically, we construct an indicator variable of whether Brazilians think corruption as the most important reason that hinders the enforcement of environmental laws. About $30 \%$ of the survey respondents thought of corruption in this manner. Corruption could also manifest itself through different channels. For instance, corruption could be the result of bad legislation where crooked officials intentionally make ineffective laws. Another possible channel could be inefficient oversight by Brazil's environmental regulating agency, the Institute for the Environment and Renewable Natural Resources. Taking these into account, we use an alternative estimation model and different measures of the dependent variable in our section on robustness checks below. We recode the dependent variable among the three main contenders - corruption, bad laws, and inefficient oversight - and examine the channels that influence Brazilian's perception of the most important reasons for the lax implementation of environmental laws.

\subsection{EXPLANATORY AND CONTROL VARIABLES}

Based on the hypotheses listed above, the main explanatory variables we use are income and education. Income is coded as an ordered variable on a five-point scale based on how much the respondent earns relative to the minimum wage, which, in January 2013 , is $\mathrm{R} \$ 667$ per month, or about US\$300. The lowest value for income corresponds to respondents who earn no income, and the highest category corresponds to a respondent who earns more than ten times the normal minimum wage. The intermediate categories reflect up to twice the minimum wage, between two and five times the minimum wage, and between five and ten times the minimum wage. Like income, the education level of the respondent is also coded as an ordered variable on a threepoint scale. The lowest category corresponds to those respondents who have completed primary school education, the next category is for those who have completed secondary school education, and the highest category is for those who have completed a university degree. 
We use age and gender of the respondent as two control variables in this study. Both variables are known to affect environmental preferences. In general, age is said to be negatively correlated with environmental concern since the younger generation is generally more active in protecting their natural surroundings, while older individuals in society typically favor a more conservative approach to support the status quo (Van Liere and Dunlap, 1981; Mohai and Twight, 1987). Similarly, women are generally known to have more concern for the environment than men, who tend to favor economic development over environmental issues. While the precise reasons for this difference are still debated, it is mostly accepted that gender differences do play a role in shaping opinion about the environment (Blocker and Eckberg, 1989; Mohai, 1992; Stern, Dietz, and Kalof, 1993). Age is coded as an ordinal variable on a seven-point scale with the lowest category for respondents less than twenty years of age, the highest category for those more than sixty years of age, and the others in between at intervals of ten years. Gender is coded as an indicator variable for a female respondent.

It is also possible that the opinion of the respondent is influenced by their political preferences (Dunlap, 1975). For instance, a respondent could think that corruption is the main reason hindering the enforcement of environmental laws in Brazil because corruption is so endemic across the political spectrum. In order to account for this, we control for the frequency with which the respondent took a candidate's proposals into account when they voted. This variable is coded on a five-point ordinal scale where the highest category corresponds to the respondent always taking a candidate's environmental positions into account followed by 'frequently', 'sometimes', 'rarely' and 'never', in that order.

In addition, it is possible that people reason about the causes of the poor enforcement of environmental laws because they think that the laws themselves are insufficient to protect the environment. Hence we control for their opinion on the sufficiency of the environmental legislation in Brazil. This variable is coded on a three-point ordinal scale where the respondents can choose between whether they think the current laws are 'too rigorous', 'adequate', or 'too lenient'. The actual wording used for the above questions in the survey is provided in the Supplementary Appendix. 
In Table 1 below we present the summary statistics for the dependent, explanatory, and control variables. It is also notable that the vast majority of Brazilians believe environmental policy is not enforced rigorously enough; the mean value is 2.71 on a $1-3$ scale, with 3 indicating the opinion that enforcement is 'too lenient'. We also provide the correlation matrix between the different variables used in this study in the Supplementary Appendix. We can observe that there is some positive correlation between education and income (0.37) and between age and income (0.27). The correlations between these variables are expected and are not so high to raise concerns about multicollinearity.

[Table 1 about here.]

We use two main estimation equations in this paper. In the first, we treat the income and education categories as ordinal categorical variables and examine whether the coefficient of the income categories are increasing. That is,

$\operatorname{Logit}\left(Y_{i}\right)=\sum_{s} \beta_{1 s} I\left(\right.$ Income $_{i} \in$ Categorys $)+\sum_{t} \beta_{2 t} I\left(\right.$ Education $_{i} \in$ Categoryt $)+\beta_{3} X_{i}+\gamma_{j}+\psi_{k}+\epsilon_{i}$

where $Y_{i}$ is the dependent variable that captures the importance of corruption in explaining the resistance towards efficient environmental law enforcement, $I(\cdot)$ represents an indicator function, $X_{i}^{\prime}$ as control variables, $\gamma_{j}$ as state level and $\psi_{k}$ as municipal level fixed effects, and $\epsilon_{i}$ as the error term. For Hypothesis 1, we test whether the coefficients of income categories are increasing, i.e. $\beta_{11}<\beta_{12}<\cdots<\beta_{15}$. For Hypotheses 2 , we test whether the coefficients of education categories are increasing, i.e. $\beta_{21}<\beta_{22}<\beta_{23}$.

In the second estimation, we treat the income and education categories as continuous variables

$$
\operatorname{Logit}\left(Y_{i}\right)=\beta_{0}+\beta_{1} \cdot \text { Income }_{i}+\beta_{2} \cdot \text { Education }_{i}+\beta_{3} \cdot X_{i}^{\prime}+\gamma_{j}+\psi_{k}+\epsilon_{i}
$$

where Income $_{i}$ and Education $i$ are the main explanatory variables, and the remaining variables $Y_{i}, X_{i}^{\prime}, \gamma_{j}, \psi_{k}$ and $\epsilon_{i}$ are the same as in the previous estimation equation. The use of logistic 
regression is useful since our aim is to compare the importance of corruption versus all other possible reasons for the loose implementation of environmental regulations. We could have also use a multinomial logistic regression model, but this depends on the baseline category chosen. In any event, we include the multinomial model as part of robustness checks.

\section{FINDINGS}

We present four sets of results. First, we present a graph that shows the proportion of respondents who thought that corruption was the main cause for the loose enforcement of environmental policy in Brazil separated by income and education. This helps to visually present correlations between the dependent variable and the main independent variables. Second, we discuss the main regression results of the study where income has a positive and statistically significant effect on corruption being an important hindrance for the implementation of environmental laws. These results are robust to the inclusion of controls as well as state and municipality fixed effects. However, the education level of the respondent is not significant in any of the models. Third, we present results from a multinomial logistic regression model where we examine different channels through which income could affect the respondent's choice. The results provide support that corruption is the primary reason for the respondent's choice, even if we allow for alternatives like bad laws or inefficient oversight. Lastly, we show a placebo test showing that the robust effect of income is specific to perceptions of enforcement, and that it is not a good predictor of environmental concern. This alleviates concerns about the possibility that wealthy people are simply more worried about the environment, and therefore emphasize corruption - something the federal government could address - as the cause of the lax enforcement of environmental policy.

\subsection{MAIN RESULTS}

There is a high degree of correlation between respondents with a higher income and their opinion of corruption as the main reason for the loose implementation of environmental policy. As Figure (1) below shows, wealthy respondents are more likely to think of corruption in this manner. This 
high correlation level is, however, absent for the respondent's education levels. There is only a slight increase in the proportion of respondents who perceived corruption as the primary reason for the lax enforcement of environmental regulations in the country. In the results that follow, we will show that the association of this perception of corruption and income levels is robust, whereas its correlation with education levels is weak and not statistically significant.

\section{[Figure 1 about here.]}

The main regression results are presented in Tables 2 and 3 below. The dependent variable in all models is an indicator of whether the respondent perceived that corruption was the main reason for the loose implementation of environmental laws. We have included the two competing explanatory variables - income and education - in all the models. Individual control variables like age, gender, role of environment in vote choice, opinion on environmental legislation as well as municipal and state fixed effects are introduced progressively. In Table 2, we treat the different categories of income and education as ordinal categorical indicator variables. We can observe that the coefficient of income increases with the income categories and is statistical significant in all models. However, the coefficient of education does not increase and is statistically insignificant in all models. These results provide support for Hypothesis 1 but not for Hypothesis 2.

[Table 2 about here.]

In Table 3, we treat income and education as continuous variables, and we can observe that income has a positive association in all models, and these effects are statistically significant at the 0.01 level throughout. Hence the main results lend support in favor of Hypothesis 1 that income is a significant predictor of whether respondents thought corruption was the reason for the loose enforcement of environmental laws in Brazil. ${ }^{8}$ In contrast, education does not have a statistically significant effect in any of the models. Although both variables are correlated, only income has an impact in our models. ${ }^{9}$ We attribute this difference to the different mechanisms of income and education in shaping the respondent's opinion. We posit that income increases the chances of experience with corruption whereas education does not necessarily do so. 
[Table 3 about here.]

Notably, these results are different from a study in Mexico City, where the poor are more vulnerable to corruption in traffic control than the rich (Fried, Lagunes, and Venkataramani, 2010). In the case of environmental policy, corruption allows wealthy individuals to avoid regulation; in the case of traffic control, the poor are more vulnerable, and so they need to pay bribes to avoid receiving a speeding ticket.

It is also worth noting that gender has a statistically significant effect on the respondent's perception about corruption. Female respondents are less likely to think that corruption is the main reason for the lax enforcement of environmental regulations in Brazil. Although we do not focus on gender in this paper, we attribute this result to gender inequality in Brazil. Women in Brazil are more educated than men, on average, but still earn less than their male counterparts. ${ }^{10}$

Since we cannot interpret coefficients directly from a logistic regression model (King, Tomz, and Wittenberg, 2000), we use model 6 in Table (3) (minus the state and municipal fixed effects) to generate Figure (2) that graphs the predicted probability of whether the respondent perceived that corruption was the main reason for the loose enforcement of environmental regulations on the respondent's income. For this substantive plot, we fix the respondent's age, education, gender, whether the environment matters for their vote choice, and their opinion on environmental legislation at the median levels in the sample, and compute the predicted probability as a function of the respondent's income. The graph shows that while respondents without income believe corruption to be the primary cause of enforcement failure with a probability slightly higher than 0.20 , this probability increases to more than 0.40 for respondents with the highest level of income.

[Figure 2 about here.]

In short, we have established that income is a statistically significant predictor of whether the respondent thought that corruption was the main reason for the lax implementation of environmental regulations in Brazil. On the other hand, we find that education is a poor predictor of this perception. In the next section, we present two sets of robustness tests to further reinforce support for hypothesis (1). 


\subsection{ROBUSTNESS}

The dependent variable in our main models was an indicator of whether the respondent thought that corruption was the primary reason for the loose enforcement of environmental laws. The survey question also included other options that relate to policy implementation, such as poorly formulated legislation and inefficiencies in oversight. To gain a better understanding of how the respondents thought about the role of corruption relative to other deficiencies in implementation, we now explicitly distinguish between these different alternative views.

To account for the above two possibilities, we present robustness tests that distinguish between these different channels. Specifically, we create an alternative measure of our dependent variable where we differentiate between respondents who chose 'corruption', 'bad laws' and 'inefficient oversight' as the primary reason for the lax implementation of environmental regulations. In the Supplementary Appendix, we present the results of a multinomial logistic regression with these different alternatives. ${ }^{11}$ Income continues to have a positive effect across all models for the 'corruption' alternative and remains statistically significant at the 0.01 . The effect is sustained even when we include control variables like age, gender, and municipal level fixed effects. The 'bad laws' alternative has income with a positive and statistically significant at the 0.05 level in models (1) and (2), but this drops to the 0.1 level as additional controls are imposed. The 'inefficient oversight' option has income with a positive effect, but is not statistically significant in any of the models.

Taken together, these results suggest that the respondents perceive corruption as a distinct cause of enforcement failure. There is no evidence that inefficient oversight, as distinguished from corruption, would cause public concern. The respondents also seem to be concerned about weaknesses in the formulation of legislation, though the confidence intervals around the estimated impact of income on this perception are wider than those around the corruption estimate. Even allowing for a lack of trust in competent policy formulation, corruption continues to worry the citizens. Among other things, this may suggest that our initial corruption result does not stem from anti-government ideology, as respondents who are against government intervention would presumably select 'bad laws' over the 'corruption' option. 


\subsection{PLACEBO TEST}

As discussed in the hypotheses section above, income could affect the respondent's perception of corruption as the main reason for lax implementation of environmental regulations in Brazil because of exposure to corrupt activities. However, income could also influence an individual's opinion on the importance of environmental policy (Scruggs, 2003). In this case, it could be that income does not change the perception of enforcement; instead, income strengthens environmental concern and causes the frustrated individual to blame corruption for failure. The real cause behind the respondent's option would be environmental concern, not income.

First, notice that in our main results in Table (3), the inclusion of the respondent's opinion on the environment does not change either the magnitude or the statistical significance of the income variable. To further rule out this possibility, we present a placebo test where we show that income does not determine a respondent's environmental policy preference. While environmental quality is often assumed to be a normal or a luxury good, additional income may have little effect in a country such as Brazil. Higher income has been shown to increase environmental concerns in wealthy countries (Franzen and Meyer, 2010), but a pro-environmental stance might only be triggered after a given absolute level of income is reached. Such a prediction is consistent with the literature on the environmental Kuznets curve (Aklin et al., 2013; Grossman and Krueger, 1995) and country-level evidence that finds a positive relation between average income and environmental views (Franzen, 2003).

In the Supplementary Appendix, we use a continuous variable that represents the frequency with which the respondent takes a candidate's environmental proposals into account before voting as the dependent variable, and shows that income is not a significant predictor of such environmental policy preferences. This lends support to the theory that income affects the respondent's perception due to corruption exposure rather than political preferences.

\section{CONCLUSION}

Many environmental policies go unenforced, and the problem is particularly severe in developing countries. While there are many reasons for this enforcement failure, corruption ranks 
high among them in importance. In democratic societies, action to remedy the problem is more likely if the public associates corruption with enforcement failure. In this context, it is important to understand the perceptions of the general public when it comes to the enforcement of environmental regulations, especially the determinants of those who think of corruption as the key reason for the lax implementation of environmental laws.

We have examined this question using data from a survey fielded in Brazil only two weeks before the Rio+20 summit. In one of the survey questions, the respondent was given a variety of reasons why environmental policies are not enforced more rigorously. We focused specifically on corruption, and found that wealthy individuals believe corruption to be a significant cause of enforcement failure. However, no such effect was found for education. We found that this relationship is robust to the addition of many controls and also provided a placebo test to show that the results are not driven by environmental concern among richer respondents. This lends support to the theory that wealthier respondents are more likely to be exposed to corruption, and are more likely to perceive corruption as being the main cause for the loose enforcement of environmental regulations in Brazil. Other than the theoretical contribution, these results also have policy implications. Since we do not find any effect for education in our study, it shows that improved awareness of the environment may not necessarily lead to the strengthening of the link between corruption and the lax enforcement of environmental policy. This could possibly be reversed with an information campaign in schools and media outlets highlighting the relationship between corruption and environmental policy in Brazil. Similarly, awareness campaigns about corruption and environmental policy could be targeted to lower income people. This would help in increasing attention to an important reason for implementation of environmental policy in Brazil.

\section{Notes}

${ }^{1}$ An exception is Aklin et al. (2013) who examine the environmental preferences of Brazilians.

${ }^{2}$ For instance, the Water and Mines Code decreed that land owners no longer had the right to water or ores that may be present on their private holdings. The reason behind this code was not to protect water and ores from exploitation by the private groups, but to transfer control of such resources to the federal government Drummond and Barros- 
Platiau (2006). Indeed, this law helped Brazil become a powerhouse in both ore mining and hydroelectricity during the second half of the twentieth century. Another example of of such a law was the Forest Code which established government control over all forests in the country. However, the implementation of this law proved difficult, and the coming decades saw the rise of the logging industry in Brazil and the resulting deforestation of the country's rainforests.

${ }^{3}$ This is not always a clear result. See Farzin (2003) for example.

${ }^{4}$ DataSenado is an official service of the Department of Research and Opinion, and its objective is "to develop research that serve[s] to strengthen communication between the Senate and the needs and desires of society." See http://www. senado.gov.br/noticias/datasenado/institucional.asp, accessed 5 Nov 2012.

${ }^{5}$ This survey does not include survey weights. We assume that the polled sample is representative of the population in Brazil, notwithstanding those who have no telephone. See the summary statistics in Table 1 for the demographic characteristics of the survey respondents.

${ }^{6}$ According to DataSenado, about $20 \%$ of the interviews were checked by trained professionals and the margin of error is 3 percent.

${ }^{7}$ While these substantive choices are indicative of the possible reasons that hinder the enforcement of environmental laws in Brazil, we do not claim that these reflect the actual reasons behind the problem. In this paper, we are interested in explaining Brazilian public opinion about the environmental law enforcement in the country, which is precisely what the survey does.

${ }^{8}$ While these results point to income having a statistically significant effect on the respondent's perception, the survey unfortunately does not include questions that ask respondents on their exposure to corrupt activities. In addition, since the survey included respondents with landline telephones only, we re-run the estimations using weights from the Brazilian census and our main findings hold in all models. These results are available in the Supplementary Appendix.

${ }^{9}$ In order to account for the correlation between the income and education variables, we present the Variance Inflation factors for the full model in the Supplementary Appendix.

${ }^{10}$ See, for example, http://www . socialwatch.org/node/14372, accessed 20 Dec 2012.

${ }^{11}$ We test the Independence of Irrelevant Alternatives assumption with the Hausman, seemingly unrelated estimation, and the Small-Hsiao tests. The results of these tests are also available in the Supplementary Appendix. 


\section{References}

Aklin, Michaël, Patrick Bayer, S.P.Harish, and Johannes Urpelainen. 2013. "Rural Development and Politics: Determinants of Private Electricity Generation in Indian States, 2001-2011." Unpublished Working Paper.

Andersen, Lykke E., and Clive W.J. Granger. 2007. "Modeling Amazon Deforestation for Policy Purposes: Reconciling Conservation Priorities and Human Development." Environmental Economics and Policy Studies 8 (3): 201-210.

Ascher, William. 1999. Why Governments Waste Natural Resources: Policy Failures in Developing Countries. Baltimore: Johns Hopkins University Press.

Asproudis, Elias. 2011. “Revisiting Environmental Groups and Members' Behaviour: Budget, Size and (Im)pure Altruism." Environmental Economics and Policy Studies 13 (2): 139-156.

Bechtel, Michael M., and Jale Tosun. 2009. "Changing Economic Openness for Environmental Policy Convergence: When Can Trade Agreements Induce Convergence of Environmental Regulation?" International Studies Quarterly 53 (4): 931-953.

Blocker, Jean T., and Douglas L. Eckberg. 1989. "Environmental Issues as Women's Issues: General Concerns and Local Hazards." Social Science Quarterly 70 (3): 586-593.

Bloom, David E. 1995. "International Public Opinion on the Environment." Science 269 (5222): 354-358.

Booth, William. 1989. "Monitoring the Fate of the Forests from Space." Science 243 (4897): 14281429.

Brechin, Steven R., and Willett Kempton. 1994. "Global Environmentalism: A Challenge to the Postmaterialism Thesis?" Social Science Quarterly 75 (2): 245-269.

Cole, Matthew A. 2007. "Corruption, Income and the Environment: An Empirical Analysis." Ecological Economics 62 (3-4): 637-647.

Cole, Matthew A., Robert J. R. Elliott, and Per G. Fredriksson. 2006. "Endogenous Pollution Havens: Does FDI Influence Environmental Regulations?" Scandinavian Journal of Economics 108 (1): 157-178.

Damania, Richard, Per G. Fredriksson, and John A. List. 2003. "Trade Liberalization, Corruption, and Environmental Policy Formation: Theory and Evidence." Journal of Environmental Economics and Management 46 (3): 490-512.

De Oliveira, Jose Antonio Puppim. 2002. "Implementing Environmental Policies in Developing Countries Through Decentralization: The Case of Protected Areas in Bahia, Brazil." World Development 30 (10): 1713-1736.

Desai, Uday, ed. 1998. Ecological Policy and Politics in Developing Countries: Economic Growth, Democracy, and Environment. Albany: State University of New York Press. 
Diekmann, Andreas, and Axel Franzen. 1999. "The Wealth of Nations and Environmental Concern." Environment and Behavior 31 (4): 540-549.

Dietz, Thomas, Paul Stern, and Gregory Guagnano. 1998. "Social Structural and Social Psychological Bases of Environmental Concern." Environment and Behavior 30 (4): 450-471.

Dobson, Stephen, and Carlyn Ramlogan-Dobson. 2012. "Why is Corruption Less Harmful to Income Inequality in Latin America?" World Development 40 (8): 1534-1545.

Drummond, José, and Ana Flávia Barros-Platiau. 2006. "Brazilian Environmental Laws and Policies, 1934-2002: A Critical Overview." Law and Policy 28 (1): 83-108.

Dunlap, Riley. 1975. “The Impact of Political Orientation on Environmental Attitudes and Actions." Environment and Behavior 7 (4): 428-454.

Dunlap, Riley E., and Angela G. Mertig. 1995. “Global Concern for the Environment: Is Affluence a Prerequisite?" Journal of Social Issues 51 (4): 121-137.

Farzin, Hossein Y., and Craig A. Bond. 2006. "Democracy and Environmental Quality." Journal of Development Economics 81 (1): 213-235.

Farzin, Y. Hossein. 2003. “The Effects of Emissions Standards on Industry." Journal of Regulatory Economics 24 (3): 315-327.

Fearnside, Philip M. 2005. “Deforestation in Brazilian Amazonia: History, Rates, and Consequences." Conservation Biology 19 (3): 680-688.

Fernandes, Edesio. 1992. "Law, Politics and Environmental Protection in Brazil." Journal of Environmental Law 4 (1): 41-56.

Fordaq. 2009. Accessed 7 December 2012.

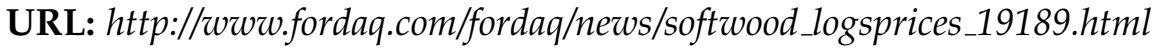

Franzen, Axel. 2003. "Environmental Attitudes in International Comparison: An Analysis of the ISSP Surveys 1993 and 2000." Social Science Quarterly 84 (2): 297-308.

Franzen, Axel, and Reto Meyer. 2010. "Environmental Attitudes in Cross-National Perspective: A Multilevel Analysis of the ISSP 1993 and 2000." European Sociological Review 26 (2): 219-234.

Fredriksson, Per G., Herman R.J. Vollebergh, and Elbert Dijkgraaf. 2004. “Corruption and Energy Efficiency in OECD Countries: Theory and Evidence." Journal of Environmental Economics and Management 47 (2): 207-231.

Fredriksson, Per G., and Jakob Svensson. 2003. "Political Instability, Corruption and Policy Formation: The Case of Environmental Policy." Journal of Public Economics 87 (7-8): 1383-1405.

Fredriksson, Per G., John A. List, and Daniel L. Millimet. 2003. "Bureaucratic Corruption, Environmental Policy and Inbound US FDI: Theory and Evidence." Journal of Public Economics 87 (7-8): $1407-1430$.

Fried, Brian J. 2012. “Distributive Politics and Conditional Cash Transfers: The Case of Brazil's Bolsa Familia." World Development 40 (5): 1042-1053. 
Fried, Brian J., Paul Lagunes, and Atheendar Venkataramani. 2010. "Corruption and Inequality at the Crossroad: A Multimethod Study of Bribery and Discrimination in Latin America." Latin American Research Review 45 (1): 76-97.

Goodland, Robert J. A., and Howard S. Irwin. 1975. Amazon Jungle: Green Hell to Red Desert? An Ecological Discussion of the Environmental Impact of the Highway Construction Program in the Amazon Basin. Amsterdam, The Netherlands: Elsevier Scientific Publishing.

Greenpeace. 2001. “Partners in Mahogany Crime: Amazon at the Mercy of 'Gentelmen's Agreements'." October 1.

URL: http://www.greenpeace.org/usa/en/media-center/reports/partners-in-mahogany-crime/

Grossman, Gene M., and Alan B. Krueger. 1995. "Economic Growth and the Environment." Quarterly Journal of Economics 110 (2): 353-377.

Guimarães, R. 1991. The Ecopolitics of Development in the Third World: Politics and Environment in Brazil. Boulder: Lynne Rienner.

Hochstetler, Kathryn, and Margaret E. Keck. 2007. Greening Brazil: Environmentalism in State and Society. Durham: Duke University Press.

Howell, Susan E., and Shirley B. Laska. 1992. "The Changing Face of the Environmental Coalition: A Research Note." Environment and Behavior 24 (1): 134-44.

Hu, Jin-Li, Chung-Huang Huang, and Wei-Kai Chu. 2004. "Bribery, Hierarchical Government, and Incomplete Environmental Enforcement." Environmental Economics and Policy Studies 6 (3): 177-96.

Hunt, Jennifer, and Sonia Laszlo. 2012. "Is Bribery Really Regressive? Bribery's Costs, Benefits, and Mechanisms." World Development 40 (2): 355-372.

Inglehart, Ronald. 1995. "Public Support for Environmental Protection: Objective Problems and Subjective Values in 43 Societies." PS: Political Science and Politics 28 (1): 57-72.

Jones, Robert E., and Riley E. Dunlap. 1992. “The Social Bases of Environmental Concern: Have They Changed Over Time?" Rural Sociology 57 (1): 28-47.

Kellman, Janelle E. 2001-2002. "The Brazilian Legal Tradition and Environmental Protection: Friend or Foe." Hastings International and Comparative Law Review 25: 145-167.

King, Gary, Michael Tomz, and Jason Wittenberg. 2000. "Making the Most of Statistical Analyses: Improving Interpretation and Presentation." American Journal of Political Science 44 (2): 341-355.

Lewinsohn, Thomas M., and Paulo Inácio Prado. 2005. "How Many Species Are There in Brazil?" Conservation Biology 19 (3): 619-624.

López, Ramón, and Siddhartha Mitra. 2000. "Corruption, Pollution, and the Kuznets Environment Curve." Journal of Environmental Economics and Management 40 (2): 137-150.

Melgar, Natalia, Máximo Rossi, and Tom W. Smith. 2010. "The Perception of Corruption." International Journal of Public Opinion Research 22 (1): 120-131. 
Mittermeier, Russel A., Gustavo A. B. Da Fonseca, Anthony B. Rylands, and Katrina Brandon. 2005. "A Brief History of Biodiversity Conservation in Brazil." Conservation Biology 19 (3): 601-607.

Mocan, Naci. 2008. "What Determines Corruption? International Evidence from Microdata." Economic Inquiry 46 (4): 493-510.

Mohai, Paul. 1992. "Men, Women, and the Environment: An Examination of the Gender Gap in Environmental Concern and Activism." Society and Natural Resources 5 (1): 1-19.

Mohai, Paul, and Ben Twight. 1987. "Age and Environmentalism: An Elaboration of the Buttel Model Using National Survey Evidence." Social Science Quarterly 68 (4): 798-815.

Moran, Emilio F. 1994. "The Law, Politics, and Economics of Amazonian Deforestation." Indiana Journal of Global Legal Studies 1 (2). Article 6.

Ohdoko, Taro, and Kentaro Yoshida. 2012. "Public Preferences for Forest Ecosystem Management in Japan with Emphasis on Species Diversity." Environmental Economics and Policy Studies 14 (2): 147-169.

Olken, Benjamin. 2007. "Monitoring Corruption: Evidence from a Field Experiment in Indonesia." Journal of Political Economy 115 (2): 200-249.

Pellegrini, Lorenzo, and Reyer Gerlagh. 2006. "Corruption, Democracy, and Environmental Policy: An Empirical Contribution to the Debate." The Journal of Environment E Development 15 (3): 332-354.

Rylands, Anthony B., and Katrina Brandon. 2005. "Brazilian Protected Areas." Conservation Biology 19 (3): 612-618.

Scruggs, Lyle. 2003. Sustaining Abundance: Environmental Performance in Industrial Democracies. New York: Cambridge University Press.

Seligson, Mitchell A. 2002. "The Impact of Corruption on Regime Legitimacy: A Comparative Study of Four Latin American Countries." Journal of Politics 64 (2): 408-433.

Seligson, Mitchell A. 2006. "The Measurement and Impact of Corruption Victimization: Survey Evidence from Latin America." World Development 34 (2): 381-404.

Setzer, Alberto W., and Marcos C. Pereira. 1991. “Amazonia Biomass Burning in 1987 and an Estimate of their Tropospheric Emissions." Ambio 20: 19-22.

Stern, Paul C., Thomas Dietz, and Linda Kalof. 1993. "Value Orientations, Gender, and Environmental Concern." Environment and Behavior 25 (5): 322-348.

Stigler, George J. 1972. “Economic Competition and Political Competition." Public Choice 13 (1): 91-106.

Sundström, Aksel. 2012. "Corruption in the Commons: Why Bribery Hampers Enforcement of Environmental Regulations in South African Fisheries." University of Gothenburg Working Paper. 
Tabarelli, Marcelo, Luiz Paulo Pinto, José M.C. Silva, Márcia Hirota, and Lúcio Bedê. 2005. "Challenges and Opportunities for Biodiversity Conservation in the Brazilian Atlantic Forest." Conservation Biology 19 (3): 695-700.

Transparency International. 2012. "Corruption Perceptions Index.".

URL: $h t t p: / / w w w . t r a n s p a r e n c y . o r g / c p i 2012 /$ results

Van Liere, Kent, and Riley Dunlap. 1980. "The Social Bases of Environmental Concern: A Review of Hypothesis, Explanations and Empirical Evidence." Public Opinion Quarterly 44 (2): 181-197.

Van Liere, Kent, and Riley Dunlap. 1981. “Environmental Concern: Does it Make a Difference how it's Measured?" Environment and Behavior 13 (6): 651-676.

Veríssimo, Adalberto, Paulo Barreto, Marli Mattos, Ricardo Tarifa, and Christopher Uhl. 1992. "Logging Impacts and Prospects for Sustainable Forest Management in an Old Amazonian Frontier: The Case of Paragominas." Forest Ecology and Management 55 (Logging Impacts and Prospects 1-4): 169-199.

Vining, Joanne, and Angela Ebreo. 1990. "What Makes a Recycler? A Comparison of Recyclers and Nonrecyclers." Environment and Behavior 22 (1): 55-73.

Welsch, Heinz. 2004. "Corruption, Growth, and the Environment: A Cross-Country Analysis." Environment and Development Economics 9 (5): 663-693.

Wittman, Donald A. 1995. The Myth of Democratic Failure: Why Political Institutions are Efficient. Chicago: University of Chicago Press.

You, Jong-Song, and Sanjeev Khagram. 2005. "A Comparative Study of Inequality and Corruption." American Sociological Review 70 (1): 136-157. 


\section{Proportion of Respondents who chose Corruption}
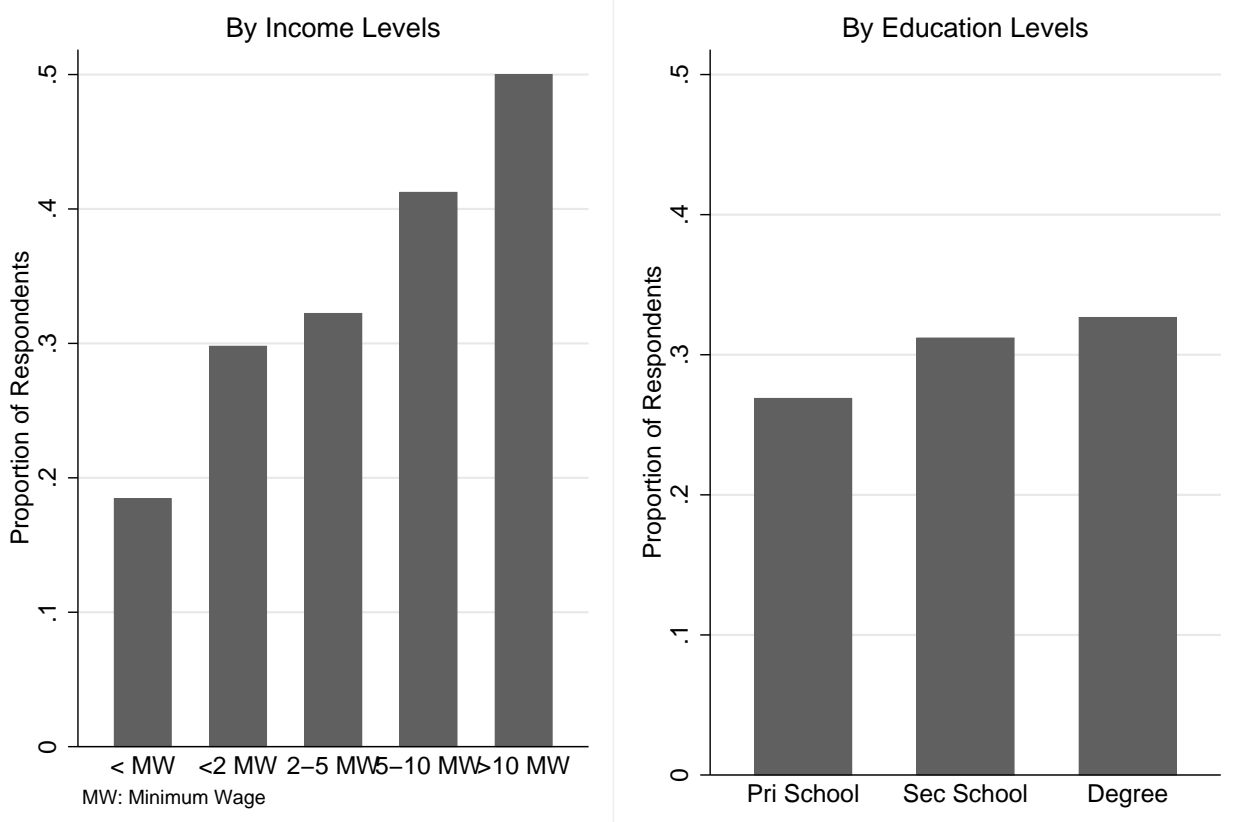

Figure 1: Proportion of Respondents Perceiving Corruption as the Primary Cause of Lax Environmental Policy Enforcement 


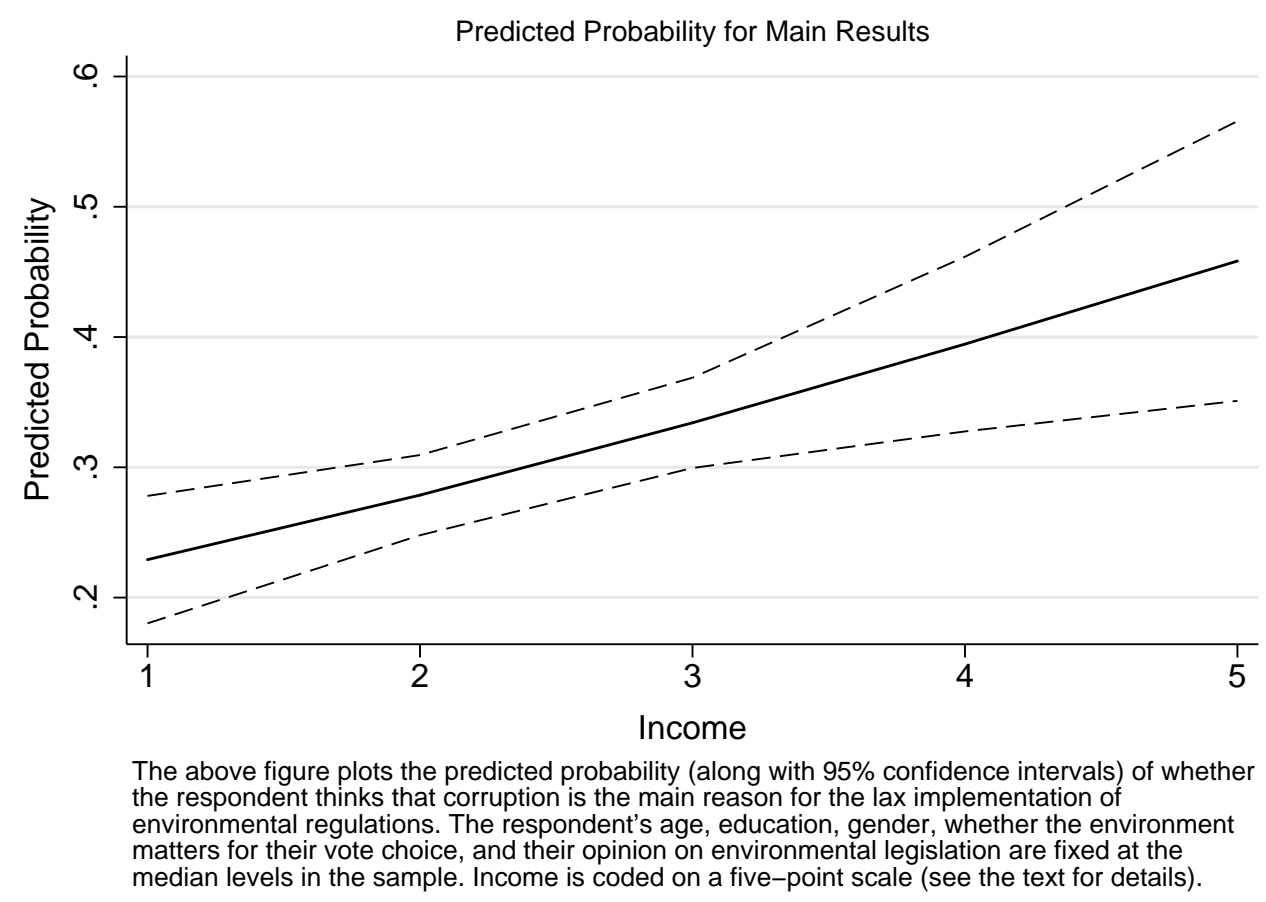

Figure 2: Predicted Probability of the Perceiving Corruption as the Primary Cause of Lax Environmental Policy Enforcement 
Table 1: Summary Statistics

\begin{tabular}{|c|c|c|c|c|c|}
\hline & mean & sd & $\min$ & $\max$ & count \\
\hline Age & 3.49 & 1.53 & 1 & 6 & 1072 \\
\hline Education & 1.97 & 0.70 & 1 & 3 & 1072 \\
\hline Income & 2.41 & 0.97 & 1 & 5 & 1072 \\
\hline Female Respondent & 0.53 & 0.50 & 0 & 1 & 1072 \\
\hline Environment Matters for Vote Choice & 1.97 & 1.22 & 1 & 5 & 1072 \\
\hline Opinion on Env. Legislation & 2.71 & 0.53 & 1 & 3 & 1072 \\
\hline \multicolumn{6}{|l|}{ Responses to Survey Question 1} \\
\hline Corruption & 0.30 & 0.46 & 0 & 1 & 1072 \\
\hline Bad Laws & 0.08 & 0.26 & 0 & 1 & 1072 \\
\hline Inefficient Oversight & 0.26 & 0.44 & 0 & 1 & 1072 \\
\hline Other Options & 0.36 & 0.48 & 0 & 1 & 1072 \\
\hline Total & 1 & & & & \\
\hline
\end{tabular}


Table 2: Main Results (with Discrete IV)

\begin{tabular}{lcccccc}
\hline & $(1)$ & $(2)$ & $(3)$ & $(4)$ & $(5)$ & $(6)$ \\
\hline 0-2 Minimum Wages (0/1) & $0.637^{* * *}$ & $0.574^{* *}$ & $0.573^{* *}$ & $0.559^{* *}$ & $0.552^{* *}$ & $0.529^{* *}$ \\
& $(0.224)$ & $(0.225)$ & $(0.225)$ & $(0.225)$ & $(0.226)$ & $(0.233)$ \\
2-5 Minimum Wages (0/1) & $0.764^{* * *}$ & $0.596^{* *}$ & $0.586^{* *}$ & $0.565^{* *}$ & $0.559^{* *}$ & $0.601^{* *}$ \\
& $(0.246)$ & $(0.254)$ & $(0.254)$ & $(0.254)$ & $(0.254)$ & $(0.264)$ \\
5-10 Minimum Wages (0/1) & $1.174^{* * *}$ & $0.993^{* * *}$ & $0.993^{* * *}$ & $0.985^{* * *}$ & $0.969^{* * *}$ & $1.032^{* * *}$ \\
& $(0.315)$ & $(0.324)$ & $(0.324)$ & $(0.323)$ & $(0.324)$ & $(0.332)$ \\
>10 Minimum Wages (0/1) & $1.526^{* * *}$ & $1.256^{* * *}$ & $1.267^{* * *}$ & $1.311^{* * *}$ & $1.299^{* * *}$ & $1.438^{* * *}$ \\
& $(0.413)$ & $(0.428)$ & $(0.426)$ & $(0.427)$ & $(0.429)$ & $(0.443)$ \\
Secondary School (0/1) & 0.159 & 0.200 & 0.183 & 0.159 & 0.154 & 0.127 \\
& $(0.172)$ & $(0.174)$ & $(0.174)$ & $(0.175)$ & $(0.176)$ & $(0.181)$ \\
Degree (0/1) & -0.023 & 0.086 & 0.065 & 0.049 & 0.042 & 0.010 \\
Age & $(0.221)$ & $(0.226)$ & $(0.226)$ & $(0.225)$ & $(0.226)$ & $(0.232)$ \\
Female Respondent & 0.007 & 0.027 & 0.024 & 0.021 & 0.022 & 0.018 \\
& $(0.048)$ & $(0.049)$ & $(0.049)$ & $(0.049)$ & $(0.049)$ & $(0.051)$ \\
Env for Vote Choice & & $-0.386^{* * *}$ & $-0.395^{* * *}$ & $-0.427^{* * *}$ & $-0.423^{* * *}$ & $-0.416^{* * *}$ \\
Opinion on Env. Legislation & & $(0.143)$ & $(0.143)$ & $(0.144)$ & $(0.144)$ & $(0.151)$ \\
& & & -0.051 & -0.046 & -0.043 & -0.061 \\
Constant & & & $(0.058)$ & $(0.058)$ & $(0.058)$ & $(0.061)$ \\
& & & & $0.276^{* *}$ & $0.276^{* *}$ & $0.296^{* *}$ \\
Municipal Fixed Effects & $-1.602^{* * *}$ & $-1.421^{* * *}$ & $-1.288^{* * *}$ & $-1.994^{* * *}$ & $-1.939^{* * *}$ & $-2.237^{* * *}$ \\
State Fixed Effects & $(0.279)$ & $(0.286)$ & $(0.324)$ & $(0.476)$ & $(0.494)$ & $(0.759)$ \\
\hline Observations & No & No & No & No & Yes & Yes \\
\hline
\end{tabular}

The dependent variable in all models is an indicator for whether the respondent thought corruption was the main reason for the lax implementation of environmental laws in Brazil. All the above models are logistic regressions. Huber-White (robust) standard errors reported in parentheses.

${ }^{*} p<0.10,{ }^{* *} p<0.05,{ }^{* * *} p<0.01$ 
Table 3: Main Results (with Continuous IV)

\begin{tabular}{lcccccc}
\hline & $(1)$ & $(2)$ & $(3)$ & $(4)$ & $(5)$ & $(6)$ \\
\hline Income & $0.327^{* * *}$ & $0.260^{* * *}$ & $0.260^{* * *}$ & $0.265^{* * *}$ & $0.262^{* * *}$ & $0.299^{* * *}$ \\
Education & $(0.080)$ & $(0.084)$ & $(0.084)$ & $(0.084)$ & $(0.085)$ & $(0.089)$ \\
& -0.037 & 0.015 & 0.003 & -0.005 & -0.009 & -0.021 \\
Age & $(0.105)$ & $(0.108)$ & $(0.108)$ & $(0.108)$ & $(0.108)$ & $(0.112)$ \\
Female Respondent & -0.006 & 0.014 & 0.011 & 0.008 & 0.010 & 0.007 \\
& $(0.047)$ & $(0.048)$ & $(0.048)$ & $(0.048)$ & $(0.048)$ & $(0.050)$ \\
Env for Vote Choice & & $-0.376^{* * *}$ & $-0.384^{* * *}$ & $-0.413^{* * *}$ & $-0.409^{* * *}$ & $-0.399^{* * *}$ \\
& & $(0.142)$ & $(0.143)$ & $(0.144)$ & $(0.144)$ & $(0.150)$ \\
Opinion on Env. Legislation & & & -0.051 & -0.044 & -0.042 & -0.059 \\
& & & $(0.058)$ & $(0.058)$ & $(0.058)$ & $(0.060)$ \\
Constant & & & & $0.279^{* *}$ & $0.278^{* *}$ & $0.294^{* *}$ \\
& $-1.538^{* * *}$ & $-1.354^{* * *}$ & $-1.219^{* * *}$ & $-1.961^{* * *}$ & $-1.895^{* * *}$ & $-2.3144^{* * *}$ \\
Municipal Fixed Effects & $(0.262)$ & $(0.273)$ & $(0.309)$ & $(0.480)$ & $(0.499)$ & $(0.764)$ \\
State Fixed Effects & No & No & No & No & Yes & Yes \\
\hline Observations & No & No & No & No & No & Yes \\
\hline
\end{tabular}

The dependent variable in all models is an indicator for whether the respondent thought corruption was the main reason for the lax implementation of environmental laws in Brazil. All the above models are logistic regressions. Huber-White (robust) standard errors reported in parentheses.

${ }^{*} p<0.10,{ }^{* *} p<0.05,{ }^{* * *} p<0.01$ 